\title{
Extracorporeal Membrane Oxygenation for Severe Refractory Respiratory Failure Secondary to 2009 H1N1 Influenza A
}

\author{
David A Turner MD, Kyle J Rehder MD, Stacey L Peterson-Carmichael MD, \\ Caroline P Ozment MD, Mashael S Al-Hegelan MBBS, Walter L Williford RRT, \\ Michelle A Peters RRT, Paul W Noble MD, and Ira M Cheifetz MD FAARC
}

\begin{abstract}
BACKGROUND: Respiratory failure and acute respiratory distress syndrome secondary to H1N1 influenza infection is a source of substantial morbidity and mortality, having caused over $\mathbf{2 6 5 , 0 0 0}$ hospitalizations in the United States in 2009. During the H1N1 pandemic, up to 31\% of the H1N1 patients required intensive care unit admission, and many were refractory to maximal conventional therapies. These most critically ill patients may require extracorporeal membrane oxygenation (ECMO) for survival. METHODS: We retrospectively reviewed the medical records of the 7 patients with refractory hypoxemia due to H1N1 influenza who were treated with ECMO in our pediatric intensive care unit. RESULTS: Five of the 7 patients survived to hospital discharge. The cohort's mean age was 21 years, and 4 were female. At admission to the pediatric intensive care unit, 6 had at least one comorbid condition, 6 were mechanically ventilated, and one was in shock. All 7 patients were treated with oral oseltamivir, high-frequency oscillatory ventilation, and inhaled nitric oxide prior to ECMO. Five received intravenous steroids, and 2 were treated with compassionate-use intravenous zanamivir. The mean duration of pre-ECMO ventilation was 8.7 days (range $14 \mathrm{~h}$ to $25 \mathrm{~d}$ ). Mean oxygenation index was 50 (range 26-73) at ECMO cannulation. Six received venovenous ECMO, and one received venoarterial ECMO. The mean duration of ECMO was 432 hours (range 192-890 h). CONCLUSIONS: This series suggests that ECMO is a viable treatment for refractory hypoxemia secondary to H1N1 influenza infection in both pediatric and adult patients. Key words: extracorporeal membrane oxygenation; ECMO; mechanical ventilation; HIN1; influenza; acute respiratory distress syndrome; ARDS; acute lung injury; respiratory failure; hypoxemia. [Respir Care 2011;56(7):941-946. (C) 2011 Daedalus Enterprises]
\end{abstract}

\section{Introduction}

Drs Turner, Rehder, Peterson-Carmichael, Ozment, and Cheifetz are affiliated with the Division of Pediatric Critical Care Medicine, Department of Pediatrics; Drs Al-Hegelan and Noble are affiliated with the Division of Pulmonary, Allergy, and Critical Care Medicine, Department of Medicine; and Mr Williford, Ms Peters, and Dr Cheifetz are affiliated with Respiratory Care Services, Duke University Hospital, Duke University Medical Center, Durham, North Carolina.

The authors have disclosed no conflicts of interest.

Correspondence: David A Turner MD, Division of Pediatric Critical Care, Duke University Medical Center, Box 3046, Durham NC 27710. E-mail: david.turner@duke.edu.

DOI: $10.4187 /$ respcare.01066
During the 2009 pandemic, most infections with H1N1 influenza were mild and self-limited, but intensive care unit (ICU) admission was required in $9-31 \%$ of the over 265,000 patients hospitalized with H1N1 infection in the

See the Related Editorial on Page 1054

United States, and mortality rate in these critically ill patients ranged from $14 \%$ to $46 \% .^{1-11}$ In many centers, extracorporeal membrane oxygenation (ECMO) was employed as a rescue strategy for refractory acute respiratory distress syndrome (ARDS) due to H1N1 infection, in both 
Table 1. Characteristics of 7 Patients With H1N1 Influenza and Acute Respiratory Distress Syndrome

\begin{tabular}{|c|c|c|c|c|c|c|c|c|c|c|c|}
\hline Patient & $\begin{array}{l}\text { Age } \\
(\mathrm{y})\end{array}$ & Sex & $\begin{array}{c}\text { APACHE II } \\
\text { or } \\
\text { PRISM III } \\
\text { Score }\end{array}$ & $\begin{array}{l}\text { Shock on } \\
\text { Admission }\end{array}$ & $\begin{array}{l}\text { Body } \\
\text { Mass } \\
\text { Index } \\
\left(\mathrm{kg} / \mathrm{m}^{2}\right)\end{array}$ & $\begin{array}{l}\text { Pre-ECMO } \\
\text { Ventilation } \\
\text { Duration (d) }\end{array}$ & $\begin{array}{l}\text { Oxygenation } \\
\text { Index Prior } \\
\text { to ECMO } \\
\text { Cannulation } \\
\text { (within } 4 \mathrm{~h} \text { ) }\end{array}$ & $\begin{array}{c}\mathrm{P}_{\mathrm{aO}_{2}} / \mathrm{F}_{\mathrm{IO}_{2}} \\
\text { Prior to } \\
\text { ECMO } \\
\text { Cannulation } \\
\text { (within } 4 \mathrm{~h}) \\
(\mathrm{mm} \mathrm{Hg})\end{array}$ & $\begin{array}{l}\text { Type of } \\
\text { ECMO }\end{array}$ & $\begin{array}{c}\text { ECMO } \\
\text { Duration (h) }\end{array}$ & Outcome \\
\hline 1 & 25 & F & 9 & No & 24.6 & 1 & 73 & 41 & Venovenous & 192 & $\begin{array}{l}\text { Survived, } \\
\text { discharged to } \\
\text { home }\end{array}$ \\
\hline 2 & 17 & F & $12 *$ & No & 27.4 & 11 & 55 & 58 & Venovenous & 890 & Died \\
\hline 3 & 24 & F & 23 & No & 27.5 & 2 & 65 & 49 & Venovenous & 563 & $\begin{array}{l}\text { Survived, } \\
\text { discharged to } \\
\text { rehabilitation }\end{array}$ \\
\hline 4 & 7 & M & $7 *$ & No & 17.5 & 6 & 26 & 53 & Venoarterial & 662 & $\begin{array}{l}\text { Survived, } \\
\text { discharged to } \\
\text { rehabilitation }\end{array}$ \\
\hline 5 & 15 & M & $17 *$ & No & 29.5 & 14 & 39 & 57 & Venovenous & 219 & $\begin{array}{l}\text { Survived, } \\
\text { discharged to } \\
\text { rehabilitation }\end{array}$ \\
\hline 6 & 25 & F & 25 & Yes & 28.4 & 25 & 43 & 69 & Venovenous & 192 & Died \\
\hline 7 & 33 & M & 19 & No & 31.6 & 1 & 51 & 66 & Venovenous & 308 & $\begin{array}{l}\text { Survived, } \\
\text { discharged to } \\
\text { rehabilitation }\end{array}$ \\
\hline $\begin{array}{l}* \text { * Pediatr } \\
\text { APACH } \\
\text { ECMO }\end{array}$ & Acu & $\begin{array}{l}\text { rtal } \\
\text { yysi }\end{array}$ & $\begin{array}{l}\text { RISM) score. } \\
\text { and Chronic I } \\
\text { prane oxygenat }\end{array}$ & h Evaluation & & & & & & & \\
\hline
\end{tabular}

adult and pediatric patients..$^{12-14}$ In the setting of refractory respiratory failure, ECMO has been an accepted and effective therapy in neonatal and pediatric patients for several decades. ${ }^{6,7,15,16}$ In addition, data illustrating the success of ECMO in adult patients with ARDS emerged during the H1N1 pandemic and became even more relevant as large numbers of H1N1 infected adolescents and young adults required ICU admission. , $^{2,17}$

When ECMO was utilized in these most severely affected young adult H1N1 patients, management occurred in the pediatric ICU (PICU) in a substantial subset of the patients because ECMO has traditionally been a neonatal and pediatric therapy, and limited infrastructure exists in some centers to provide ECMO outside of the PICU, pediatric cardiac ICU, or neonatal ICU. In this report we describe the epidemiology, clinical characteristics, treatment course, and outcomes of 7 adult and pediatric patients treated with ECMO in our PICU for refractory respiratory failure and ARDS secondary to H1N1 influenza infection.

\section{Methods}

After institutional review board approval, we retrospectively identified 7 patients with H1N1 influenza infection and severe respiratory failure who required life-support with ECMO. These patients were all managed in the PICU during ECMO. We reviewed their medical records with attention to demographics, underlying comorbidities, course of influenza infection, mechanical ventilation modes and strategies, laboratory values, adjunctive therapies, ECMO course, and outcome.

\section{Results}

In our institution, 169 adults and children required hospital admission for H1N1 influenza infection during late 2009 and early 2010, and 39 (23\%) were admitted to intensive care units. Seven of these 39 critically ill patients required ECMO for refractory respiratory failure and ARDS, and 5 of those 7 patients survived to hospital discharge (Table 1). The cohort's mean age was 21 years (median $24 \mathrm{y}$, range 7-33 y). The 4 adult patients' Acute Physiology and Chronic Health Evaluation II score range was 9-25. The Pediatric Risk of Mortality III scores of the 3 patients $<18$ years of age were 7,12, and 17. Four of the 7 patients were female, and 6 patients had an underlying medical condition prior to hospitalization for H1N1 infection (Table 2). The cohort's mean body mass index was $26.6 \mathrm{~kg} / \mathrm{m}^{2}$ (median $27.5 \mathrm{~kg} / \mathrm{m}^{2}$, range $17.5-31.6 \mathrm{~kg} /$ $\mathrm{m}^{2}$ ).

All 7 patients were diagnosed based on positive polymerase-chain-reaction test for influenza A type H1N1. At PICU admission, 6 of the patients were mechanically ven- 
Table 2. Comorbidities

\begin{tabular}{lc}
\hline \hline & No. \\
\hline Systemic lupus erythematosus & 2 \\
Congenital heart disease & 1 \\
Renal insufficiency & 1 \\
Plastic bronchitis, bronchopulmonary aspergillosis, & 1 \\
$\quad$ history of left lower lobectomy & \\
Obesity* & 1 \\
Pregnancy & \\
& \\
$*$ Obesity $=$ body mass index $>30 \mathrm{~kg} / \mathrm{m}^{2}$ in adults, or $>95$ th percentile in children. & \\
\hline
\end{tabular}

tilated, and one required vasoactive agents for hemodynamic support. The mean duration of mechanical ventilation prior to ECMO initiation was 8.7 days (median $6 \mathrm{~d}$, range $14 \mathrm{~h}$ to $25 \mathrm{~d}$ ). At PICU admission, all 7 patients met the criteria for severe ARDS: mean $\mathrm{P}_{\mathrm{aO}_{2}} / \mathrm{F}_{\mathrm{IO}_{2}} 56 \mathrm{~mm} \mathrm{Hg}$. The mean oxygenation index within 4 hours of ECMO cannulation was 50 (median 51, range 26-73) (see Table 1). Prior to ECMO cannulation, all 7 patients were on high-frequency oscillatory ventilation and inhaled nitric oxide, and none received surfactant or were placed in the prone position. Prior to ECMO cannulation, 5 patients received at least one dose of steroids, but the type of steroid and dosing differed greatly. All 7 were treated with oral oseltamivir, and 2 were additionally treated with compassionate-use intravenous zanamivir.

Six of the patients underwent venovenous ECMO. The patient with underlying hypoplastic left-heart syndrome underwent venoarterial ECMO. Table 3 shows the mean ECMO flows at 4 hours and 24 hours, and the ventilation variables at 24 hours. The mean duration of ECMO was 432 hours (median $308 \mathrm{~h}$, range 192-890 h). Table 4 shows the complications that developed during ECMO. The mean duration of mechanical ventilation (until tracheostomy tube placement or extubation) was 37 days (median $36 \mathrm{~d}$, range 14-45 d), . The mean duration of hospitalization was 62 days (median $36 \mathrm{~d}$, range 33-102 d).

Of the 5 patients who survived to hospital discharge, 4 were discharged initially to a rehabilitation facility, and one was discharged directly home. At the time of hospital discharge, 2 of the 5 survivors had not returned completely to their neurologic baseline, as evidenced by mild cognitive and fine motor dysfunction. All 5 ECMO survivors were ultimately discharged home, at which time only one required ongoing respiratory support.

\section{Discussion}

Throughout 2009, H1N1 influenza infection led to a considerable number of critically ill patients, as many as $30 \%$ of whom were refractory to maximal conventional respiratory therapies. ${ }^{1,4,6-9,12}$ In our 7 patients with refractory respiratory failure secondary to H1N1, ECMO was successful, and 5 of the 7 patients survived. This finding consistent with published survival rates for ECMO worldwide during the H1N1 pandemic and suggest that ECMO is a viable therapy in both pediatric and adult patients with respiratory failure and refractory ARDS. ${ }^{12-14}$

Consistent with prior reports that the H1N1 influenza attack rate was highest in adolescents and young adults, 2,18 6 of our patients were between 15 and 33 years old. Additionally, all but one of those 6 patients had an important underlying comorbidity, including the one patient under the age of 15, who had hypoplastic left-heart syndrome and had undergone the Fontan operation. Given the substantial risk factors in these patients, the fact that their ARDS was progressive and unresponsive to standard ICU therapies was not surprising.

The pre-ECMO therapies in our patients included a lungprotective ventilation strategy, initially with primarily pressure controlled synchronized intermittent mandatory ventilation and a target tidal volume of $5-7 \mathrm{~mL} / \mathrm{kg}$. Because of disease progression, all 7 patients were transitioned to highfrequency oscillatory ventilation and then to ECMO, following a brief bridge with inhaled nitric oxide (Table 5). In addition, we used intravenous steroids in 5 of the patients, and oral oseltamivir in all 7 patients. However, patients 2 and 4 did not begin oral oseltamivir within 48 hours of symptom onset. Following ECMO initiation, patients 4 and 7 also received compassionate-use intravenous zanamivir.

Because of the expansion and evolution of our ECMO program during the H1N1 pandemic, ${ }^{19}$ these 7 patients were managed with 2 different ECMO systems. Patients 1 through 4 were treated with a 3 Stockert rollerhead pump system (Sorin Group, Arvada, Colorado) and a Quadrox D oxygenator (Maquet, Hirrlingen, Germany). Patients 5 through 7 were treated with a Rotaflow centrifugal pump and Quadrox D oxygenator (both from Maquet, Hirrlingen, Germany). With both systems we used a standardized protocol of continuous heparin infusion titrated based on activated clotting time. Following ECMO initiation and improvement of gas exchange, the level of mechanical ventilatory support was immediately weaned to rest the lungs and minimize ongoing secondary injury. Despite expected variations in mode and settings, all 7 patients, within 24 hours of ECMO cannulation, were on $\mathrm{F}_{\mathrm{IO}_{2}} \leq 0.50$, peak inspiratory pressure $<29 \mathrm{~cm} \mathrm{H}_{2} \mathrm{O}$, and a target tidal volume of $5-7 \mathrm{~mL} / \mathrm{kg}$ (see Table 3 ).

While this series demonstrates successful use of ECMO for refractory respiratory failure from H1N1 influenza in several complex patients, further data are needed to determine under what circumstances ECMO is appropriate. We feel that ECMO deserves broad consideration in critically ill neonatal, pediatric, and adult patients, even if the pa- 
Table 3. ECMO Flows and Ventilation Variables

\begin{tabular}{|c|c|c|c|c|c|c|c|c|}
\hline \multirow[b]{2}{*}{ Patient } & \multicolumn{2}{|c|}{ ECMO Flow (L/min) } & \multirow{2}{*}{$\begin{array}{l}\text { Ventilation } \\
\text { Mode* }\end{array}$} & \multirow{2}{*}{$\begin{array}{l}\text { Respiratory Rate } \\
\text { (breaths/min)* }\end{array}$} & \multirow[b]{2}{*}{$\mathrm{F}_{\mathrm{IO}_{2}}{ }^{*}$} & \multirow{2}{*}{$\begin{array}{c}\text { Peak } \\
\text { Inspiratory } \\
\text { Pressure } \\
\left(\mathrm{cm} \mathrm{H}_{2} \mathrm{O}\right)^{*} \\
\end{array}$} & \multirow{2}{*}{$\begin{array}{c}\text { PEEP } \\
\left(\mathrm{cm} \mathrm{H}_{2} \mathrm{O}\right)^{*}\end{array}$} & \multirow{2}{*}{$\begin{array}{c}\text { Mean } \\
\text { Airway } \\
\text { Pressure } \\
\left(\mathrm{cm} \mathrm{H}_{2} \mathrm{O}\right)^{*}\end{array}$} \\
\hline & $\begin{array}{c}\text { At } \\
4 \text { Hours }\end{array}$ & $\begin{array}{c}\text { At } \\
24 \text { Hours }\end{array}$ & & & & & & \\
\hline 1 & 2.61 & 3.19 & PC SIMV & 12 & 0.3 & 25 & 10 & 12 \\
\hline 2 & 2.92 & 3.22 & PC SIMV & 16 & 0.5 & 29 & 12 & 17 \\
\hline 3 & 3.16 & 3.09 & PC SIMV & 20 & 0.5 & 25 & 10 & 14 \\
\hline 4 & 1.29 & 1.39 & PC SIMV & 15 & 0.4 & 25 & 10 & 14 \\
\hline 5 & 3.32 & 3.61 & PC SIMV & 15 & 0.4 & 27 & 12 & 15 \\
\hline 6 & 3.92 & 4.32 & APRV & 6 & 0.4 & 25 & 0 & 22 \\
\hline 7 & 4.20 & 4.22 & APRV & 9 & 0.4 & 28 & 0 & 24 \\
\hline
\end{tabular}

Table 4. Complications During ECMO

\begin{tabular}{lr}
\hline \hline & No. \\
\hline Renal failure* & 3 \\
Cannula site bleeding & 2 \\
Infection & 1 \\
Pulmonary hemorrhage & 1 \\
& \\
* New renal failure that required in-line renal replacement therapy during extracorporeal & \\
membrane oxygenation (ECMO). & \\
\hline
\end{tabular}

tient has important comorbidities. The impact of comorbidities is unclear, but ECMO can unquestionably be a life-saving therapy in many circumstances. The possibility of saving the lives of these most severely affected patients with refractory respiratory failure suggests that there are few absolute contraindications to ECMO.

Prospective identification of patients who will benefit from ECMO remains quite difficult, despite decades of successful use in a wide range of clinical settings. $6,7,12,14,15,20$ In the setting of refractory respiratory failure, however, reported ECMO survival is lower when lung injury is associated with comorbidities, especially in the setting of substantial immunocompromise or multiple organ dysfunction. ${ }^{6,7,21}$ Our series demonstrates that ECMO can be successful in the presence of considerable underlying comorbidities in pediatric and adult patients, thus potentially expanding the pool of ECMO candidates. Given this potential benefit, it is important to evaluate the patient's ECMO eligibility early, since some data suggest that early application of ECMO may lead to a shorter ECMO course and more rapid lung recovery. ${ }^{1}$ The time needed for lung recovery on ECMO, and resource availability are important considerations in the expansion of ECMO utilization, especially during a pandemic.

Time required on ECMO may be impacted by both underlying comorbidities and pre-ECMO duration of me- chanical ventilation. The mean ECMO course in this series was 432 hours, which is longer than the 280 hour mean ECMO duration for ARDS secondary to H1N1 reported by the Extracorporeal Life Support Organization. ${ }^{21}$ Our patients' comorbidities may have contributed to their time on ECMO, but their pre-ECMO duration of mechanical ventilation may also have been a factor.

The largest reported series of H1N1 ECMO patients had a mean of 2 days of mechanical ventilation prior to ECMO initiation. ${ }^{12}$ In our series, 3 patients rapidly deteriorated, consistent with rapid progression of respiratory failure seen in many patients with $\mathrm{H} 1 \mathrm{~N} 1$ infection, and were cannulated for ECMO in less than 48 hours. ${ }^{2}$ Despite these 3 patients with rapid deterioration, the mean duration of mechanical ventilation prior to ECMO initiation was 8.7 days (median $6 \mathrm{~d}$, range $14 \mathrm{~h}$ to $25 \mathrm{~d}$ ). A substantial contributor to the mean duration of mechanical ventilation prior to ECMO was the duration of ventilation in the 2 non-survivors, who were ventilated for 11 days and 25 days prior to transfer to our PICU for ECMO. This point raises the important issue of transfer criteria and timing of transfer to an ICU capable of providing ECMO support.

One non-survivor initially had improved pulmonary compliance and gas exchange but later developed a severe superinfection with Pseudomonas aeruginosa and consequent septic shock, necessitating ECMO. At the time of cannulation, she had been ventilated for 25 days, and her H1N1 viral culture and respiratory viral polymerase-chainreaction test had become negative, which suggests that her ECMO course was not directly related to the H1N1 infection. Factors that probably contributed to her death were sepsis at the time of ECMO cannulation, active bacterial infection, and prolonged pre-ECMO ventilation duration, all of which are associated with higher ECMO mortality. ${ }^{21-24}$

The other non-survivor in this series required ventilatory support for 11 days at a referring institution prior to 
Table 5. Pre-ECMO HFOV Variables*

\begin{tabular}{|c|c|c|c|c|c|c|}
\hline Patient & $\begin{array}{l}\text { Mean Airway Pressure } \\
\left(\mathrm{cm} \mathrm{H}_{2} \mathrm{O}\right)\end{array}$ & $\begin{array}{l}\text { Amplitude } \\
\left(\mathrm{cm} \mathrm{H}_{2} \mathrm{O}\right)\end{array}$ & $\begin{array}{l}\text { Frequency } \\
\quad(\mathrm{Hz})\end{array}$ & Power & $\begin{array}{c}\text { Bias Flow } \\
(\mathrm{L} / \mathrm{min})\end{array}$ & $\begin{array}{l}\text { Inhaled Nitric Oxide } \\
\text { Peak Concentration } \\
\text { (ppm) }\end{array}$ \\
\hline 1 & 30 & 72 & 5.5 & 6.5 & 30 & 20 \\
\hline 2 & 32 & 64 & 5.0 & 4.0 & 25 & 20 \\
\hline 3 & 32 & 72 & 5.5 & 6.0 & 30 & 20 \\
\hline 4 & 24 & 46 & 7.0 & 4.0 & 20 & 20 \\
\hline 5 & 32 & 50 & 4.0 & 4.0 & 35 & 20 \\
\hline 6 & 30 & 87 & 4.0 & 8.0 & 30 & 20 \\
\hline 7 & 34 & 87 & 5.0 & 7.0 & 30 & 10 \\
\hline
\end{tabular}

ECMO. However, the possible benefit of earlier ECMO initiation in this patient is unclear, given that her underlying comorbidities included plastic bronchitis, bronchopulmonary aspergillosis, and a history of left lower lobectomy. This patient's limited pulmonary reserve and fragile baseline respiratory state surely contributed to the severity of her H1N1 infection, the need for ECMO, and death, despite 890 hours on ECMO.

Of note, one patient did survive despite a pre-ECMO ventilation course of 14 days, but for his entire course in our PICU he was treated with a lung-protective strategy that included predominantly high-frequency oscillatory ventilation. Many experts consider a ventilation duration greater than approximately one week a contraindication to ECMO because of the potential for irreversible lung injury. ${ }^{22-24}$ However, the "acceptable" duration of mechanical ventilation prior to ECMO initiation is unclear in the current era of lung-protective ventilation. While it is certainly possible that the prolonged pre-ECMO ventilation impacted mortality and duration of ECMO, our experience in this series suggests that patients should not be uniformly excluded from consideration for ECMO based solely on the duration of pre-ECMO ventilation.

Another important consideration in the determination of ECMO candidacy is underlying comorbidity. Consistent with prior reports, our cohort had a high incidence of comorbidities (see Table 2). It is clear from this series that ECMO can be successful in H1N1 ARDS patients with comorbid conditions, including congenital heart disease, renal insufficiency, connective tissue disease, and obesity, which previously would have precluded ECMO for refractory respiratory failure.

The success in this series would argue for a broader consideration of how comorbidities should impact ECMO candidacy in refractory respiratory failure. We recognize that these patients may require longer ECMO courses and that recovery of lung function may depend on the preECMO duration of ventilation. While ECMO certainly involves substantial resources and risks, clinical series in which ECMO successes continue to be reported in previously unthinkable circumstances further complicate the ECMO decision making process.

\section{Conclusions}

We report the successful utilization of ECMO for refractory respiratory failure and ARDS in a series of adult and pediatric patients with H1N1 influenza. Five of our 7 patients survived, which adds to the body of literature supporting the notion that ECMO is a viable therapy for refractory ARDS in both pediatric and adult patients. Based on these data, we recommend broadening ECMO consideration to include more complex patients who previously may have not been considered ECMO candidates.

\section{REFERENCES}

1. ANZIC Influenza Investigators, Webb SA, Pettilä V, Seppelt I, Bellomo R, Bailey M, et al. Critical care services and 2009 H1N1 influenza in Australia and New Zealand. N Engl J Med 2009;361(20): 1925-1934.

2. Bautista E, Chotpitayasunondh T, Gao Z, Harper SA, Shaw M, Uyeki TM, et al. Clinical aspects of pandemic 2009 influenza A (H1N1) virus infection. N Engl J Med 2009;362(18):1708-1719.

3. Jain S, Kamimoto L, Bramley AM, Schmitz AM, Benoit SR, Louie $\mathrm{J}$, et al. Hospitalized patients with 2009 H1N1 influenza in the United States, April-June 2009. N Engl J Med 2009;361(20):1935-1944.

4. Kumar A, Zarychanski R, Pinto R, Cook DJ, Marshall J, Lacroix J, et al. Critically ill patients with 2009 Influenza A(H1N1) infection in Canada. JAMA 2009;302(17):1872-1879.

5. Lurie N. H1N1 influenza, public health preparedness, and health care reform. N Engl J Med 2009;361(9):843-845.

6. Green TP, Timmons OD, Fackler JC, Moler FW, Thompson AE, Sweeney MF. The impact of extracorporeal membrane oxygenation on survival in pediatric patients with acute respiratory failure. Pediatric Critical Care Study Group. Crit Care Med 1996; 24(2):323-329

7. Nehra D, Goldstein AM, Doody DP, Ryan DP, Chang Y, Masiakos 


\section{ECMO for Severe Refractory Respiratory Failure From 2009 H1N1 InfluenZa A}

PT. Extracorporeal membrane oxygenation for nonneonatal acute respiratory failure: the Massachusetts General Hospital experience from 1990 to 2008. Arch Surg 2009;144(5):427-432.

8. Perez-Padilla R, de la Rosa-Zamboni D, Ponce de Leon S, Hernan$\operatorname{dez}$ M, Quinones-Falconi F, Bautista E, et al. Pneumonia and respiratory failure from swine-origin influenza $\mathrm{A}(\mathrm{H} 1 \mathrm{~N} 1)$ in Mexico. N Engl J Med 2009;361(7):680-689.

9. Rello J, Rodriguez A, Ibanez P, Socias L, Cebrian J, Marques A, et al. Intensive care adult patients with severe respiratory failure caused by influenza A (H1N1)v in Spain. Crit Care 2009;13(5):R148.

10. Chowell G, Bertozzi SM, Colchero MA, Lopez-Gatell H, AlpucheAranda C, Hernandez M, et al. Severe respiratory disease concurrent with the circulation of H1N1 influenza. N Engl J Med 2009;361(7): 674-679.

11. Zimmer SM, Burke DS. Historical perspective-Emergence of influenza A (H1N1) viruses. N Engl J Med 2009;361(3):279-285.

12. ANZ ECMO Influenza Investigators; Davies A, Jones D, Bailey M, Beca J, Bellomo R, et al. Extracorporeal membrane oxygenation for 2009 influenza A(H1N1) acute respiratory distress syndrome. JAMA 2009;302(17):1888-1895.

13. Buckley E, Sidebotham D, McGeorge A, Roberts S, Allen SJ, Beca J. Extracorporeal membrane oxygenation for cardiorespiratory failure in four patients with pandemic H1N1 2009 influenza virus and secondary bacterial infection. Br J Anaesth;104(3):326-329.

14. Freed DH, Henzler D, White CW, Fowler R, Zarychanski R, Hutchison J, et al. Extracorporeal lung support for patients who had severe respiratory failure secondary to influenza A (H1N1) 2009 infection in Canada. Can J Anaesth 2010;57(3):240-247.

15. Green TP, Moler FW, Goodman DM. Probability of survival after prolonged extracorporeal membrane oxygenation in pediatric patients with acute respiratory failure. Extracorporeal Life Support Organization. Crit Care Med 1995;23(6):1132-1139.
16. Pettignano R, Fortenberry JD, Heard ML, Labuz MD, Kesser KC, Tanner AJ, et al. Primary use of the venovenous approach for extracorporeal membrane oxygenation in pediatric acute respiratory failure. Pediatr Crit Care Med 2003;4(3):291-298.

17. Peek GJ, Mugford M, Tiruvoipati R, Wilson A, Allen E, Thalanany $\mathrm{MM}$, et al. Efficacy and economic assessment of conventional ventilatory support versus extracorporeal membrane oxygenation for severe adult respiratory failure (CESAR): a multicentre randomised controlled trial. Lancet 2009;374(9698):1351-1363.

18. Estenssoro E, Rios FG, Apezteguia C, Reina R, Neira J, Ceraso DH, et al. Pandemic 2009 influenza A in Argentina: a study of 337 patients on mechanical ventilation. Am J Respir Crit Care Med; 182(1):41-48.

19. Turner DA, Williford WL, Peters MA, Thalman JJ, Shearer IR, Walczak RJ, et al. Development of a collaborative program to provide extracorporeal membrane oxygenation for adults with refractory hypoxemia within the framework of a pandemic. Pediatr Crit Care Med 2010 [epub ahead of print]

20. Dalton HJ, Rycus PT, Conrad SA. Update on extracorporeal life support 2004. Semin Perinatol 2005;29(1):24-33.

21. Extracorporeal Life Support Organization. ECLS Registry Report. January 2010.

22. Moler FW, Palmisano J, Custer JR. Extracorporeal life support for pediatric respiratory failure: predictors of survival from 220 patients. Crit Care Med 1993;21(10):1604-1611.

23. Pierre EJ, Zwischenberger JB, Angel C, Upp J, Cortiella J, Sankar A, et al. Extracorporeal membrane oxygenation in the treatment of respiratory failure in pediatric patients with burns. J Burn Care Rehabil 1998;19(2):131-134.

24. Pranikoff T, Hirschl RB, Steimle CN, Anderson HL 3rd, Bartlett RH. Mortality is directly related to the duration of mechanical ventilation before the initiation of extracorporeal life support for severe respiratory failure. Crit Care Med 1997;25(1):28-32.

This article is approved for Continuing Respiratory Care Education credit. For information and to obtain your CRCE

(free to AARC members) visit www.RCJournal.com 